\title{
Technology in Education: Looking Back from 2020
}

\author{
Shayan Doroudi
}

It is certainly unusual to write a "book review" for a book published 32 years ago, but in this case, I think it is warranted. As evident from the title of the book-Technology in Education: Looking Toward 2020 (Nickerson and Zodhiates, 1988) -its purpose is to speculate about what the role of technology could and should be in education in the year 2020. So in some sense, this book is as relevant now, in 2020, as it was over 30 years ago. At the time of its writing, its relevance was in suggesting what the future of education should look like, but now its relevance is as an artifact for studying the "history of the future of education" (Watters, 2015). Moreover, this book is a collection of chapters written by leading researchers, not just in the field of educational technology, but in the field of education in general. For example, six of the fifteen authors are members of the National Academy of Education (David Cohen, Andrea diSessa, Howard Gardner, Roy Pea, Lauren Resnick, and Alan Schoenfeld), two of whom were Presidents of the American Educational Research Association (Resnick and Schoenfeld). ${ }^{1}$ Other authors from various backgrounds bring in a diversity of perspectives, including a perspective on diversity and equity by Shirley Malcom, who received the National Academy of Science's most prestigious award, the Public Welfare medal, for her work on improving diversity in science education. At the very least, it should be interesting to reflect upon what such prominent researchers thought about the role of technology in present-day education three decades ago. But as I will soon make clear, the relevance of the book today is more than just as a "historical artifact"; the content of the book is quite remarkable and much of it is still relevant in its own right.

However, despite the prominence of the authors and the important ideas contained in this book, it seems to have been undervalued and understudied, with a little over a hundred citations for the book and less than 600 citations for all of the individual chapters of the book collectively. To my knowledge, no book review was written when it was first published, so perhaps a retrospective book review is now in order. By looking back, not only can we see how similar (or dissimilar) the state of education is to the visions and predictions of these researchers, but by seeing how their visions did or did not come to pass we can learn lessons for charting the future again. After all, hindsight is $2020^{2}$

I begin by reflecting on the book's contents and structure-as in a typical book review-and claiming that some of the chapters are still of relevance to educational discourse today. I then examine how the book's visions have played out over the past three decades. By building on arguments presented by two of the authors, David Cohen and Shirley Malcom, I discuss two impediments that have thwarted otherwise noble visions from coming true: the organization of schools and concerns around equity. To mitigate these concerns, I contend we must not only focus on creating new technologies for education, but also focus on designing socio-technical environments that are attuned to the needs of stakeholders to ensure technology plays a meaningful and equitable role in the future of education. I finally move on to discuss another area in which the authors of this book were perceptive: even if technological tools do not drastically change educational practice, technology is changing society as we speak, and education-as an agent of societal reform-must account for technological change in order to keep up with the times.

\section{The Book's Contents}

The origins of Technology in Education were in a "2020 Panel" convened on October 15-17, 1986 in Manchester Village, Vermont by the Educational Technology Center of the Harvard Graduate School of Education. The directors of the Educational Technology Center appointed Raymond Nickerson and Philip Zodhiates to lead the panel. Nickerson sent out a paper to the panelists to prime their thinking about the future of technology in education

\footnotetext{
${ }^{1}$ Interestingly, all of these authors except Resnick joined the National Academy of Education after the book was published, so perhaps the authors were less recognized then than they are now.

${ }^{2}$ The organizers of the effort that resulted in this book acknowledged this pun when choosing the year to focus on (pp. viii-ix).
} 
in the United States ${ }^{3}$ and "to propose a perspective for thinking about the future, not so much with the intent of predicting it as with that of helping to shape it" (p. 1). The panelists were asked to each write a paper in advance of the panel. The chapters of Technology in Education include Nickerson's introductory paper, revised versions of each of the panelists' papers, and a concluding chapter by Nickerson. The underlying assumptions behind the premise of the panel were that

There are many possible futures... Not all possible futures are equally probable. Not all possible futures are equally desirable. What is most desirable among the possibilities is not necessarily most probable in the absence of some concerted effort to make it so. (p. 1)

One of the key observations that Nickerson made was that

The first question we should ask is not "What can technology do?" but rather "What should be done?" Starting with the feasibility question runs the risk of selecting the problem to fit the solution in hand, which may not be the problem one should be trying to solve. The fact that technology makes a particular educational objective feasible is not, by itself, an adequate reason for establishing that objective.” (p. 3)

Indeed, one of the remarkable things about this book is that the authors of the panel followed this charge to put educational goals first. Some authors spent the majority of their chapter discussing educational concerns before even bringing up technology (Pea and Gardner). Others intersperse how technology could help throughout their chapter but note that technology is a tool, not a driver, for their vision for education. Thus, this work, unlike many others in this genre, is not plagued with technocentrism, a term (Papert, 1988) coined around when this book was published to describe what he saw as the prevalent approach to (educational) technology at the time.

Given the thoughtfulness of the contributors to this volume, a number of the chapters constitute what I consider great standalone works that carry insights that are relevant and informative to this day. Indeed, several of these chapters are perhaps worth assigning in courses on educational technology. I will briefly describe three of these below.

Pea's chapter constitutes a rather thorough exposition of the problem of knowledge transfer (at the expense of having a chapter much longer than most others), before re-defining transfer by taking an interpretive and cultural lens. In doing so, Pea noted how transfer is not merely a cognitive phenomena, but should only be expected to take place when it is culturally and socially appropriate. To this end, he re-interpreted Thorndike's "common elements" 4 as being socially constructed. What makes this chapter especially useful is that Pea grounded his new theory of transfer by building off of the cognitive framework and showing its insufficiency, rather than discussing transfer in terms of participationist or situative terms, which can lead to cognitivists and situativists speaking past each other (Greeno, 1997; Anderson et al., 1997). While Pea's notion of transfer is thought-provoking, his ideas for how to technologically support it are only loosely formed sketches. Interestingly, I think they can still serve as guides for how to develop technology to support knowledge transfer in the present day, but given their vagueness, it is not clear how influential they would be.

While Pea's chapter lays out a theory of learning that he thought should drive technology development, Resnick and Johnson's chapter shows how cognitive theories were already influencing the design of educational technology in the 1980s. Even though the technologies they talk about in their chapter are outdated, and in many cases, forgotten, their chapter stands the test of time in terms of how cognitive science influences educational technology to the present day. The principles they outline include: making certain cognitive processes (like reading) more automatic by having students practice individual components before the integrated whole, scaffolding a task by having the computer complete parts of the task, diagnosing errors, fostering the induction of correct rules, and linking multiple representations to build robust mental models. Indeed, these principles are relevant to this day, and this chapter, along with the (at times simple) technologies it describes, illustrates that sometimes simple ideas that are grounded in learning theory could make a technology more effective, a lesson worth reiterating in 2020.

Finally, Cohen's chapter presents a clear argument for why school organization limits the impact of educational technology, by drawing on the history of educational technology. I discuss Cohen's contribution at length below, but suffice it to say for now that it remains an excellent introduction to how political and organizational considerations must be thought of alongside technological impact. I assign both Resnick and Johnson's chapter

\footnotetext{
${ }^{3}$ Some of the discussion in the book and this review focus specifically on the US educational system, but I believe most of the discussion applies more broadly.

${ }^{4}$ This refers to Thorndike's theory that knowledge transfers between two problems or situations to the extent that they share common elements.
} 
and Cohen's chapter in my undergraduate class on educational technology. Despite these chapters being written over thirty years ago and being longer than many of the assigned readings, several students found one or the other to be among the most useful readings in the course ${ }^{5}$.

While these and other standalone contributions are noteworthy, this book is more than just the sum of its parts. Indeed, some of the chapters contain content that has been published elsewhere by the authors, but the collection as a whole remains unique. The bookending chapters by Nickerson provide a unified focus and synthesis of themes and concerns that appear throughout the chapters. Authors also occasionally refer to other contributions in the volume, though perhaps the work could have contained more cross-author discussion. It is not clear how the chapters were organized, but the change in perspectives from one chapter to another makes for an enjoyable read. For example, immediately after Cohen's pessimistic chapter, one finds perhaps the most optimistic chapter, interestingly enough written by a teacher (Jim Minstrell). Cohen made an argument for why inquiry-based education, despite its advantages, will not make its way into mainstream classrooms, in part due to teachers' attitudes towards uncertainty and sharing authority with students. In the following chapter, Minstrell, a teacher, laid out a futuristic vision of education that focuses on inquiry-based learning and gives students tremendous autonomy in their own education as they interact with an intelligent teacher's assistant. On the one hand, it seems their visions could not be more different from one another, but I will revisit how to reconcile these visions in what follows.

\section{0: Then and Now}

We now turn to reflecting on how close the visions laid out in this book are to the current state of technology in education. In short, I would say that none of the visions are close to what education looks like today, with the exception of two pessimistic predictions offered by Cohen and Malcom. I will return to these two perspectives shortly, but first it is worth discussing what the other authors did get right.

\section{The Technology of 2020}

By and large, the authors had a fairly keen sense of what technology would look like in 2020, so it is not the case that they were either overly futuristic or conservative in terms of technological advancements. In the opening chapter, Nickerson gave a list of technological trends that he anticipates will exist by 2020. Here are a few:

- Computer systems that realize orders of magnitude increases in computing power by exploiting parallel multi-processor architectures will become increasingly common.

- Remote wireless terminals will provide access to computer networks and thereby to central repositories of information of nearly every conceivable type.

- Microcomputer-based computing power will be everywhere-in household appliances, in hand tools, in games and toys, in clothing...

- Computer-based information services addressed to a diversity of objectives-job posting, want ads, selective news, information searches-will also proliferate (p. 2).

In the concluding chapter, Nickerson did make some broader speculations about future technology that have not come true yet, such as "It could be possible to travel anywhere on earth in less than two hours" (p. 286), but these kinds of predictions do not have any bearing on the visions of education made in the book.

I believe one of the reasons Nickerson and the other authors in this book made realistic predictions is that they do not speculate too much about the state of artificial intelligence (AI), and hence did not overestimate its role in education. The technological predictions made in the book were typically extrapolated from trends in hardware growth (such as Moore's Law) and likely changes in software. Landauer explicitly stated, "The view of the future that I offer is predicated on an optimistic assessment of probable progress but does not depend on an uncritical acceptance of hyperbolic claims for artificial intelligence or imaginary hardware devices" (p. 12). When it came to speech recognition and understanding, Nickerson perceptively acknowledged, "How soon truly natural-language capabilities will be available is difficult to say; however, systems with useful aspects of natural language and limited speech input and output capabilities will proliferate" (p. 2). This is in contrast to overly

\footnotetext{
${ }^{5}$ The first time I taught the course, twelve out of thirty five students found Cohen's chapter to be among the three most useful readings out of over twenty five choices, making it tied for the most appreciated reading in the course. Strangely, the second time I taught the course, none of the students found it to be among the three useful readings. This could be due to the fact that it was assigned when students were thrust into remote instruction and dealing with other stressors during the COVID-19 pandemic, and as such preferred shorter readings.
} 
optimistic predictions that have been made throughout the history of AI (Nilsson, 2009). For example, Firschein et al. (1973) surveyed experts in the field of AI to predict when various AI applications would be developed. To cite their most relevant finding for our purposes, they found that the median expert predicted that a robot tutor that "would not be a simple-minded CAI-programmed learning device, but on a level with a good human teacher" would be commercially available by 1988 (the year Technology in Education was published).

Even in Minstrell's futuristic vision of a teacher's assistant that tracks students, makes predictions about students' understandings, and makes recommendations about what the student knows, the various pieces of the teaching assistant (TACFU) are not too far from educational technologies that exist today. Moreover, Minstrell preempted certain concerns and limitations of such technologies and the need to design around them, including

- the need for interpretability in automated inferences ("TACFU responds with data, both anecdotal and statistical, to support each psychological inference" [p. 270]),

- the need for educational data privacy ("out of respect for individual freedom, students may choose not to $\log$ on, and they may choose to erase any portion of their recorded interaction at any time. Such a choice would limit the profile of understandings and capabilities in each student's record, bu this is a price one has to be willing to pay for remaining a free society." [p. 269]),

- the importance of mixed initiative instructional decision-making ("Between TACFU's input and his own, Matt decides what activities to recommend to the student. From these several suggestions, the student will choose her or his assignment." [p. 271]),

- and the limitations in natural language understanding ("some students still do not relate to a machine and TACFU still has trouble understanding their language and their thinking. The program is not yet as receptive to free response as it might be" [p. 271]).

\section{Educational Goals for 2020}

As I mentioned earlier, the authors generally put educational goals ahead of technological possibility. If their visions have not panned out, one explanation could be that their educational goals were not ideal. However, I would say their goals are quite noble, and in many cases, goals that we would ideally still aspire to today (which makes sense given the authors are reputable education scholars). I cite a few examples below.

Schoenfeld advocates for focusing on teaching the process of mathematics-which he claims will be fairly constant over time-rather than the product of mathematics-which he claims will change over the next few decades as it has changed drastically in the past 100 years. In addition to teaching domain knowledge, he advocates for teaching heuristic strategies, metacognitive strategies (which he separates into executive control during problem solving and learning strategies), and beliefs about the domain. Indeed he illustrates that these are not just important for mathematics education, but for any problem solving domain, including writing. Although I am no expert in mathematics education, I think it is safe to say that the focus of mainstream mathematics education in the US has not drastically changed over the past 30 years to encompass these higher-level skills and beliefs.

diSessa argues that in the information age it could be easy to get caught up in the idea that we need to acquire a lot more than before to keep up, but rather "what we need is a little bit more wisdom, not a dramatically increased ability to keep up with an ever-escalating pile of pure information" (p. 44), alluding to T. S. Eliot's words:

Where is the Life we have lost in living?

Where is the wisdom we have lost in knowledge?

Where is the knowledge we have lost in information? (Eliot, 1963)

To achieve this, he sets a number of more concrete goals, including focusing on depth in some areas rather than just focusing on breadth, teaching topics that are aesthetically interesting and motivating for students, and teaching mid-level knowledge (i.e., neither higher-level thinking and learning skills nor domain knowledge, but rather knowledge that may be particular to a domain that gives insights and a framework for situating and understanding other knowledge in the domain). diSessa recognizes that some might argue if these should be the goals we set, especially when it comes to aesthetics, but indeed these kinds of ideas have had advocates and continue to have advocates among educational theorists and others. However, I would say that mid-level knowledge is perhaps less often advocated for or at least not as well articulated as diSessa; indeed, it could help explain students' lack of wisdom in many domain areas. 
Gardner's educational goal is similar to diSessa's in that he argues each child should explore one or a few areas in significant depth, but his main premise is that those areas should be aligned to each child's interests and type of intelligence (drawing from his theory of multiple intelligences). He lays out a detailed vision for how one might go about enabling each student to experience depth in their topics of choice, while simultaneously attaining breadth at various points in their education. Wallace Feurzeig makes a similar argument that each student should acquire a practice and that classrooms should foster an apprenticeship model.

One might challenge over-emphasizing depth at the cost of breadth, and I will return to this point later, but for now, it suffices to say that (a) these authors did not advocate for abandoning breadth in the curriculum, and (b) the call for greater depth in learning is still one being made to this day (Mehta and Fine, 2019; Parker et al., 2013).

\section{If Neither Technology Nor Education, Then What?}

If the authors in this contribution were more or less accurate in predicting the technological state of 2020 and laid out well-founded educational visions, then why have their visions not come true? The answer lies, at least in part, in Cohen's chapter. Cohen made a powerful argument for how school organization has and will limit the impact of technologies as compared to what a policy-agnostic vision might anticipate, echoing Cuban (1986). To do so, he recounted much of the history of educational technology, which has been filled with disappointments after initial hypes (again, channeling Larry Cuban's voice). These are trends that some have been recently pointing out again in response to new hypes around MOOCs and other emerging technologies (Ferster, 2014; Watters, 2015; Reich, 2020).

Cohen began by recounting an educational technology we are all familiar with: books. He pointed out that books are a very flexible technology:

Each student can read at his own pace, with few queuing problems. Readers can flip back and forth for particular points, or review, with great ease. Books can be carried around and used at the student's discretion, read for hours at a time, studied in bits on subways and buses, or put aside for consultation with a teacher. They can be used individually or in groups. (p. 233)

Incidentally, some of these are exactly the same arguments used to promote the modern use of videos instead of live lectures. For example, when Khan (2011) reminisced about making YouTube videos for his cousins as a predecessor to Khan Academy, he noted:

If they have to review something that they should have learned a couple of weeks ago, or maybe a couple of years ago, they don't have to be embarrassed and ask their cousin. They can just watch those videos; if they're bored, they can go ahead. They can watch at their own time and pace.

Similarly, Anant Agarwal, spoke of such flexibility as a similar advantage of the popular MOOC provider, edX:

Now the students can watch these on their own campuses in their own dorm rooms at their own time and pace. Just imagine, you can pause and rewind a lecture, which you can't do in a classroom. You can watch this at midnight, and we find that the largest amount of access happens between midnight and 2:00 am." (High, 2014)

But as Cohen noted, books were not used flexibly in schools. Generally, only textbooks were used, and they were generally used as a full curriculum for a course. Although in the early 19th century books were positioned to reform the practice of teaching whereby "whole-class work-dominated by teacher talk and slates-could be reduced [and] classrooms could move away from lecture and recitation to more individualized work," lectures remained an integral part of classroom instruction, but books became a new tool by which teachers could lecture. Similar trends continued into the twentieth century even after increased publishing of diverse educational materials.

The most interesting part of the story is an apparent paradox: it is precisely the flexibility of books that made them widespread, even though they were not used flexibly. As Cohen observed, "the very attribute that innovators thought would revolutionize education made it easy for schools to adapt this innovation to existing organization and purposes" (p. 235). If books "can be used individually or in groups," teachers can simply use them individually to supplement their lectures. If books can be read at different paces, the teacher can simply specify the amount 
that students have to read in a certain number of days. Even if students can go back to review earlier material, to the extent that their self-regulatory skills are not fostered (and enough time to review is not given to them), they are unlikely to go back to a page that was assigned weeks ago.

Cohen then goes on to note that educational television had not seen uptake in K-12 education because the programming did not fit in well with existing curricula. However, in big universities, recorded videotapes of instructor lectures saw uptake because they could supplant the need for lectures (with the same advantages as YouTube videos noted earlier). Videotaped lectures could not gain prominence in K-12 education, Cohen speculates, because a big part of education at that level is watching over children. Flipped classrooms are a modern-day solution to this problem.

So, what about computers? Computers are also an incredibly flexible technology, and, thus, they are found in classrooms today. But at the same time, to the extent that they are flexible, they will not be used in the most promising, revolutionary ways, including some of the ways that the authors in this volume have suggested. Another way to look at it is that not all computer-based technologies are flexible, and as such, those technologies will be less likely to see wide-scale adoption. For example, mastery-based instruction is difficult to mesh with existing school organization; what does the teacher do with students who are all working on different parts of a curriculum? The flipped classroom helps with this somewhat, but the onus is on the teacher to figure out how to manage such a diverse classroom. There are success stories, but it is simply easier for many teachers to teach in the traditional way, than to deal with self-paced mastery learning. Even when mastery learning is used, teachers may need to move students before they are ready to keep up with the rest of the classroom (Ritter et al., 2016).

\section{The Core and the Margins}

Cohen's argument was not that innovations and reforms never happen, but rather that they are quite rare, slow, and superficial in "the core" of educational organizations, namely traditional sections of schools. Rather, innovations are much more likely to occur in what he calls "the margins" of educational organizations, such as special education classes, honors classes, and Advanced Placement programs. Innovations happen on the margins "by defining a distinctive clientele and a distinctive instructional approach, and enclosing them in an organizational subunit that is not seen as central to the organization's work." As Cohen and Mehta (2017) have recently argued, we can extend this definition to the margins of the broader educational enterprise, including private schools, innovative charter schools, homeschooling, museums, etc. Similarly, (Mehta and Fine, 2019) recently found in their impressive study of American high schools, that deeper learning is typically not found in core class, but in the peripheries. Interestingly, this idea that Cohen put forth in the 1980s in the context of educational technology, has only recently re-emerged in the broader educational reform literature (by Cohen and his colleagues, no less).

Cohen cited a number of factors that compromise a traditional classroom, which largely still exist to the present day and which will limit the types of technologies that can permeate the core and the ways these technologies are used. These include standard class sizes, class periods of fixed length, teacher-centered instruction, the nature of individual work where students complete worksheets at their desk, and beliefs about knowledge and learning (e.g., "Knowledge is represented as the mastery of bits of information, and isolated, mechanically mastered skills. Intellectual performance is represented as the correct recapitulation of those bits, and display of the skills."). Cohen observes that as a result of these factors, computer-based instruction typically results to drill-and-practice instruction in core institutions. Computers can be used in more innovative ways, but only when schools relax some of these constraints, which may in turn place them in the margins.

So in returning to the visions to the rest of the authors, their visions have not permeated the core of instructional institutions because they constitute a radical departure from traditional schooling, even if we all agree that their visions are worthwhile. For example, Gardner's vision requires a complete re-organization of school curricula, alternating between years allocated to "increasingly deep penetrations into areas of interest and inclination" and years "tailor-made for depth" (p. 33). His vision also requires new roles for the school and broader ecosystem including assessment specialists, student-curriculum brokers, and school-community brokers, and master teachers who oversee subject teachers. Schoenfeld and diSessa's visions require math and science teachers to teach important areas of problem-solving (e.g., mid-level skills, heuristics, and learning strategies), when frankly many teachers even lack concrete understandings of domain knowledge. Interestingly, these kinds of reforms are difficult not because of their over-reliance on technology (which I did not even mention when describing these visions), but because they are deep reforms of school organization, which Cohen's argument naturally extends to. Minstrell's vision turns schooling on its head even more radically (e.g., allowing for students to work from home or at school as they please) and is more technologically sophisticated, and hence even less likely to come true, but no- 
tice that while his vision is certainly not commonplace in schools, some aspects of it might be found in tech-savvy, inquiry-based schools on the margins. Indeed, Minstrell is an extreme case of a teacher on the margins in that not only is he an innovative teacher, but he has also engaged in impactful research in the learning sciences after Technology in Education was published. If innovative uses of technology backed by learning sciences principles are to be found in any classrooms, it would be in ones like Minstrell's.

Cohen and Mehta (2017) suggested several characteristics of successful reforms that can mitigate these organizational hurdles. In short, reforms need to be attuned to the needs and constraints of stakeholders as well as their beliefs, attitudes, and values.

\section{Inquiry-Based Learning}

Cohen also makes an extensive argument for why inquiry-based instruction will not permeate schools, despite being advocated for by many academics and education researchers, including Dewey and Bruner. He argues that despite the advantages of inquiry learning, it is difficult for students and difficult for teachers to implement, requiring a deeper understanding on behalf of teachers who could then pass that understanding to students. But on top of these pragmatic concerns, inquiry learning challenges norms about how teachers, students, parents, and society think about the nature of knowledge and learning. As Cohen said, the primary conceptions of knowledge and teaching are that knowledge is constituted of a bunch of facts and "the teachers [voice] is a voice for authoritative knowledge ... a pipeline for Truth" (p. 257). Challenging these deeply held preconceptions is challenging; even if a teacher disagrees, convincing parents who do not want their children to challenge their authority could be difficult. Moreover, Cohen argues that the research advocating for inquiry learning is taking place in the academy, in ivory towers that are far removed from on-the-ground, especially K-12, educational organizations. Thus, these ideas would again not penetrate the core of educational organizations.

Perhaps things have changed a bit in the past 30 years, in terms of knowledge about instructional practices being more disseminated throughout educational organizations. Indeed, many teachers advocate for constructivist and discovery-based approaches. However, even recently, schools and teachers that espouse the use of these practices were often found to not use them in practice (Mehta and Fine, 2019). Another change in recent years is the emergence of research-practice partnerships (RPPs), a growing methodology in education research that involves working directly with educational organizations over a long period of time to improve outcomes that the organizations value (Coburn and Penuel, 2016). RPPs have the potential to cause long-term changes and reforms in particular schools or districts. However, perhaps we can view schools that participate in RPPs as operating on the margins. Networked improvement communities may offer the ability to reach a wider scope of organizations, though it is not clear that even then they will extend beyond the margins (i.e., schools and districts willing to participate in improvement science innovations).

Moreover, I think Cohen's argument ignores a key reason that might have mitigated the impact of inquirybased practices in schools to the present day: not all researchers agree on the relative benefits of inquiry-based learning. Indeed, many education researchers (particular from the cognitivist tradition), are strongly in favor of direct instruction (Kirschner et al., 2006; Tobias and Duffy, 2009; Munter et al., 2015). Thus, popular societal beliefs about the nature of knowledge and learning and the role of the teacher still have many advocates among learning scientists. To the extent that the academy cannot reach a consensus on what instructional practices are best, we definitely cannot expect schools to implement the best innovations in teaching and the best technologies to support student learning.

\section{0: The Year that Changed Everything}

Indeed, until early 2020, Cohen's arguments could fairly accurately explain the state of affairs. Technological reforms were slow to make their way into core educational organizations, and when they did make their way it was because they could reinforce existing pedagogical and institutional practices. Many technological reforms and promising new technologies have been proposed that either (a) died out, (b) are being used in ways that do not look very different, beyond a superficial level, from how schools operated in the 1980s, or (c) are only adopted in the margins of schooling (Watters, 2015; Reich, 2020). But perhaps the authors of Technology in Education could not have picked a more ironic year to focus on; by March 2020, technology's role in education changed worldwide, because the world got caught up in a global pandemic. ${ }^{6}$ Almost overnight (although the exact night varied from place to place), K-12 schools, colleges, and universities transitioned to remote instruction. Distance education, a

\footnotetext{
${ }^{6}$ This section was added to the paper after an earlier draft of the paper was completed. Had I written this line then, I would have thought I was writing science fiction.
} 
model that most people had heard of but few had actually participated in for formal education, became the norm, rather than a niche.

While this may seem to contradict Cohen's analysis, it can actually be re-framed to fit the analysis. An exogenous force (i.e., the COVID-19 pandemic) drastically changed the organizational structure of schooling; what was once in the margins, now became the core. Teachers, instructors, and administrators needed to scramble to find the right technological tools for the job. Tools like Zoom and Google Classroom became favorites, because they make it easy for teachers to follow traditional forms of teaching, such as lecturing and assigning homework. Thus, while technology enabled us to move schools away from brick-and-mortar campuses and into students' homes, for the most part it reinforced existing practices. While some teachers might innovate and try to use new technological tools (or use tools like Zoom in more creative ways), these teachers are operating on the margins (in relation to even this "new core" of remote instruction); these same teachers, were probably innovating in their brick-and-mortar classrooms, whether by using technology or by using innovative pedagogical practices that did not require technology.

But is this "new core" of schooling here to stay? When schools go back to conducting in-person classes, will teachers be more likely to adopt technology in the classroom? Assuming schools will be organizationally similar to how they were in the past, Cohen's argument would suggest that the answer is "no." It is true that some educators may have adopted new technologies, such as software that provides supplementary or personalized instruction, and they may want to take those technologies back into the classroom after the pandemic. But even then, organizational hurdles may prevent well-meaning intentions. Many educational technology providers are offering their services for free or at discounted prices during the COVID-19 pandemic, but once in-person classes become mainstream again, school administrators might be reluctant to purchase licenses to various technologies (and if they do, they will likely see little use over time).

While the effect of the COVID-19 pandemic on schooling is unprecedented in scale, we must not forget about prior emergency uses of educational technology. As Watters (2020) "reminds" us, in 1937, the Chicago Public Schools were faced with a polio outbreak and for two weeks, they relied on the educational technology of the era to continue schooling. They used the radio to deliver instruction to students' homes (synchronous instruction) and newspapers to deliver assignments (asynchronous instruction), in much the same way that teachers are using video-conferencing tools and instructional packets or learning management systems today. In fact, in some countries with limited Internet access, the radio and television are still being used to provide remote instruction Kuwonu (2020). The 1937 polio outbreak and other crises did not result in lasting technological change in the way we conduct schooling. But they did make one thing clear: there are serious inequities in who could access technologies in these crises. As Watters (2015) quotes from the Chicago Daily Tribune in the outset of the polio outbreak, "it is probable that the students who benefit by the radio lessons will be those who need them the least and would suffer least by curtailment of their classroom instruction." Indeed, it was found that only 50\% of students tuned in to the radio broadcasts. These inequities have become clear once again during our current pandemic. The fact of the matter is, inequities in technology usage (and of course, inequities in education) do not just exist in a crisis; crises just bring these issues to the forefront (for a short amount of time). This is another prediction, or perhaps warning, that was made vividly in Technology in Education, a warning that we did not heed until recently.

\section{(In)equitable Futures}

Malcom laid out two possible futures for the state of education in 2020. In one, Raul Gomez goes to school only because he has to, and finds himself repeatedly bored doing drill-and-practice instruction on the computer. Because he is bored, he occasionally

deliberately answers a question incorrectly so he could see the funny little graphics built in to "motivate the user."... He had figured out other ways to solve the problems, but for some reason the computer never explained it his way. They both got the same answer, but he knew there must be something wrong with his way because the computer never did it like that. (p. 214)

Raul does not have a computer at home because his family cannot afford to buy one, but he has engaged with one at the Saltmans' home, where his mother works, and he knows computers could be used to for more interesting activities. Although he has some general interests and curiosities motivated by things he encounters outside of school, his teacher tells him she doesn't have time to discuss those because they have "to stay on schedule or they wouldn't cover the material in time for the science test" (p. 214). 
In the second possible future, Sonia Ramirez just used a computer to publish her first illustrated book on rain shadows, a topic she was interested in. Although she couldn't speak English after migrating to the US three years ago, she used the computer's speech synthesis tools to become competent in English and Spanish. She can loan a school computer to continue doing work on her book or for other educational activities at home. She and her classmates had also created computer programs, and do research on topics that interest them in their spare time.

One interesting aspect of these two visions is that, for the most part, both could have probably been stories from classrooms in the 1980s; the state of technology is not really what differentiates the two, but rather the way those technologies are utilized. Malcom noted that in the first vision, "differences in educational uses of technology further separate the worlds" (p. 215) of the privileged and the unprivileged. "On the other hand, Sonia Ramirez has been empowered by education, and the technology has made that education more meaningful and more accessible" (p. 215). She then predicted that the first vision is the more likely one of coming true.

Indeed, there are many aspects of Raul's classroom that hold in technology-rich classrooms of today. Students often show boredom when using technology, and as such may game the system and learn less Baker et al. (2010). Computers do not always understand student's correct or incorrect but informed ways of doing things, leading to confusion and frustration. While it is true that computers are quite prevalent in today's society, those of us who have the privilege of using computers all the time may forget that access is not universal. A 2015 survey found that $5 \%$ of families in the US with children under the age of 18 do not have any computer in their household (desktop, laptop, or handheld device) and 15\% have no internet subscription Ryan and Lewis (2017). These numbers are lower for underrepresented minorities than for White and Asian families.

But the story goes beyond access. Malcom was perceptive in saying "differences in educational uses of technology" separate the privileged from the unprivileged. Indeed, recent research has shown that even when there is equal access, "Schools serving privileged students tend to use the same technologies in more progressive ways than schools serving less privileged students" (p. 3) (Reich and Ito, 2017). For example, mirroring Malcom's narratives, Rafalow (2018) recently showed that three schools where students had similar levels of access to digital technology, had very different outcomes in terms of how teachers encouraged students' use of technology:

At a school serving working-class Latino youth, students are told their digital expressions are irrelevant to learning; at a school with mostly middle-class Asian American youth, students' digital expressions are seen as threats to their ability to succeed academically; and at a private school with mainly wealthy white youth, students' digital skills are positioned as essential to school success. (p. 1416)

Such differences are rooted in teachers', parents', and students' beliefs about the nature of learning, academic success, and technology. Thus, in line with Cohen's observations, reforms are more likely to happen in some educational institutions than others depending on the beliefs and attitudes of stakeholders as well as other sociocultural forces at play. However, even when a school is open to particular reforms, inequities may still exist among different social groups within the school. For example, Sims (2014) found that different groups of students may adopt "differentiating practices" around technology and its use towards learning, as a result of existing social structures and practices, even when students have equal levels of access and skills around technology use.

While most of the visions outlined in this book are not inherently inequitable, a broader takeaway from Malcom's chapter that we can retrospectively take, is that if technology and the broader socio-technical systems that encapsulate them are not designed with equity explicitly in mind, inequitable outcomes can creep in. Indeed, recent literature on fairness in machine learning has shown how data-driven algorithms can be inequitable even when the algorithm designers have no ill intent (Barocas et al., 2019). Unfortunately, Malcom's concern has seemingly not been taken seriously. Equity has been largely ignored in the design of recent educational technologies. Paulo Blikstein pointed out in his keynote at the 2018 International Conference on Artificial Intelligence in Education (AIED) that the word "equity" was mentioned only once in the proceedings of the conference since 2001. Seemingly only recently has attention been drawn towards equity and diversity; the theme of the 2019 AIED conference was "Education for All in the XXI Century," the theme of the 2019 International Learning Analytics \& Knowledge Conference was "Learning Analytics to Promote Inclusion and Success," and the theme of the 2020 International Educational Data Mining Conference was "Improving Learning Outcomes for All Learners." These are great first steps, but in order to make meaningful strides towards developing technologies for all, we must develop concerted efforts where designers of educational technologies take into account socio-cultural forces and the needs of various stakeholders-including underprivileged and minoritized groups-when designing and deploying new technologies (Reich and Ito, 2017). 


\section{Technology as An Agent of Social Change}

Thus far, I have mostly been focusing on the role of educational technology in 2020. But as the authors of this book have recognized, educational technology, namely using technology as a means of improving education, is only one role of "technology in education." In addition to the methods of teaching and learning, Nickerson mentions three other roles that technology can play in education:

Education takes place within a socio-cultural context, the nature of which is determined by technology as much as by anything else. To the extent that the purposes of education are determined by the context in which it occurs, technology, by virtue of its role as an agent of social change, is a force in shaping them. Technology also affects the content of education, because among the objectives of education is that of making understandable the world in which one lives, and we live in a technological world. (p. 285, emphasis in original)

Here I want to focus on how technology shapes the context and as a result how it might influence the purpose and content of education. Although technology has not changed schooling very much, it has changed and continues to change society drastically. Technological change is inevitable, so our educational systems must understand and productively respond to such change.

\section{(Over)extended Memory}

The Internet and how readily information can be accessed using it, is one area that has had tremendous impact on society. One might expect that Internet-enabled information access would have also had a profound impact on education, but it seemingly has not changed much, especially in formal educational systems, in part due to the reasons outlined by Cohen. Indeed, several of the authors in Technology in Education speculated about how new modes of information access could change learning as we know it. Landauer stated:

Putting books on-line in "hypertext," or in some other much better form that makes them vastly easier to navigate and learn from may change things dramatically. Suppose you have a book in which you can find just the information you want when you need it, that if asked leads you trough questions and exercises, or to background, explanatory, or related material. Suppose you have a library composed of such wonderful books, all interconnected and jointly indexed. Then you might do much more of your learning on your own than you do now. If learning on you own were made much easier, education as we know it, which consists largely in providing guidance and discipline, might whither. (p. 15)

Nickerson concurs that people might be capable of learning much more as a result of new tools for information retrieval and other technologies:

As Landauer points out, our current primary means of knowledge acquisition-reading coupled with library access-is excruciatingly slow. We really do not know what we are capable of learning and cannot rule out the possibility that, with much more powerful techniques for storing, accessing, and representing information, for assessing what people know, and for combining instruction and exploration in mutually reinforcing ways, the capability might be very much greater than our experience to date would lead us to believe. (pp. 291-292)

Indeed, the Internet and hypertext are incredibly flexible technologies. Around the same time that Technology in Education was written, Spiro et al. (1991) similarly postulated that:

The computer is ideally suited, by virtue of the flexibility it can provide, for fostering cognitive flexibility. In particular, multidimensional and nonlinear hypertext systems, if appropriately designed...have the power to convey ill-structured aspects of knowledge domains and to promote features of cognitive flexibility in ways that traditional learning environments (textbooks, lectures, computer-based drill) could not. (p. 24)

Yet following Cohen's paradoxical conclusion, it is precisely this flexibility that has led to often "lazy" uses of the computer and the Internet, both on the part of those who create content and those who consume it. Many resorted to making websites that are very much like physical print, with occasional links to other websites. There are of course websites and perhaps educational sites that leverage the power of hypertext and easy information 
access to help students learn in novel ways, but these sites (which I cannot even think of off the top of my head) are on the margins of the Internet.

But there is another impact of the Internet on learning, and that is its impact on memory. To make the case, let us begin with an earlier technology as Cohen did, namely books and the printing press. Yates (1966) and Eisenstein (1980) argue that printing has led to less need for memory devices and "mnemotechnics" or what Yates refers to as "the art of memory." Most of us probably have no memory of what these memory arts were. According to Yates (1966):

We moderns who have no memories at all may, like the professor, employ from time to time some private mnemotechnic not of vital importance to us in our lives and professions. But in the ancient world, devoid of printing, without paper for note-taking or on which to type lectures, the trained memory was of vital importance. And the ancient memories were trained by an art which reflected the art and architecture of the ancient world, which could depend on faculties of intense visual memorisation which we have lost. (p. 4)

Long before the printing press, (Plato, 1925 [c. 370 BC] ) remarked about the effect of the written word on memory through a parable:

"This invention, O king" said Theuth,"will make the Egyptians wiser and will improve their memories; for it is an elixir of memory and wisdom that I have discovered." But Thamus replied, "Most ingenious Theuth ... this invention will produce forgetfulness in the minds of those who learn to use it, because they will not practice their memory. Their trust in writing, produced by external characters which are no part of themselves, will discourage the use of their own memory within them. You have invented an elixir not of memory, but of reminding; and you offer your pupils the appearance of wisdom, not true wisdom, for they will read many things without instruction and will therefore seem to know many things, when they are for the most part ignorant and hard to get along with, since they are not wise, but only appear wise."

Coming to more modern technology, Sparrow et al. (2011) ran four studies that show the Internet and web search have made people less reliant on their memory, since they have access to information at their fingertips. For example, in one study after answering a series of trivia questions, participants had slower reaction times when naming the color that computer-related terms were written in as compared to the color of general terms. The slower reaction time indicates that computer-related terms were more accessible to the participants than other terms. The effect was seemingly larger for hard trivia questions, but still persisted even for easy trivia questions, indicating that factual recall primes people to think about computers, even if subconsciously. The authors' other studies show that when participants expected that information will be accessible in the future, they were more likely to remember where information was stored than remembering the information itself. Sparrow et al. (2011) conclude that "The Internet has become a primary form of external or transactive memory, where information is stored collectively outside ourselves." More recently, Marsh and Rajaram (2019) have pointed out other effects that the Internet could be having on memory and cognition. Of course, these considerations may not be surprising for education researchers who have long held to theories of distributed cognition (Salomon, 1993; Hutchins, 1995) or extended mind (Clark and Chalmers, 1998); the Internet and books simply extend our cognition and memory outside of our individual minds.

Even if we have the world at our fingertips, which would seemingly imply learning experiences abound, the fact that information is so readily available may make many of us find less of a need to learn altogether. Extending Resnick and Johnson's view of technology as cognitive extenders, having access to information in one's "extended memory" could be considered educational itself, replacing the need to learn that information directly. Of course, diSessa, Eliot, and others might challenge this by saying that information is not the same as knowledge and wisdom. Moreover, if a lot of information is misinformation and if fake news spreads faster than true news, as recent research suggests (Vosoughi et al., 2018), relying on Internet access to "recall" might lead to misinformed conclusions. If algorithms are deciding what information we recall most readily, then perhaps our "memory" is being twisted by politics and voices that we may disagree with.

Beyond all this, information access by itself is not very useful, if we do not have the knowledge and useful frameworks to (a) situate and construct new knowledge and (b) know what kind of new information we need to seek and where to look for that information. Wineburg (2018) argues in his book Why Learn History (When It's Already on Your Phone) that history is not just a bunch of facts, as it is often taught, but rather we need 
to teach historical thinking to enable students to make sense of information they can seek on their phones. In the domain of reading, Wolf (2018) argues that in order to engage in deep reading, readers need background knowledge, and as we offload our memory to the Internet, our background knowledge diminishes which in turn decreases how much we learn by reading in a negative feedback loop. Landauer also alludes to this in his chapter: "the digestion of information from reading and its transformation into useful new thoughts or problem solutions depends on the possession of vast amounts of prior knowledge with which to interpret it. Thus, having lots of knowledge is an important tool for acquiring and using more knowledge, as well as for its own direct application" (pp. 12-13). Information access can enable new ways of learning and thinking, but to take advantage of that, as educators, we cannot abandon teaching foundational knowledge and the critical thinking skills to make use of existing knowledge and construct new knowledge.

Therefore, while new technology has not drastically changed how we teach and learn, it has changed how we interact with knowledge, and unless education changes in order to accommodate technological change, technology might not only not empower learners, it may actually lead to negative learning outcomes. One way to mitigate the potentially negative effects of the Internet on memory and learning, is to empower learners to more productively search for, use, and learn from the information around them. In other words, we need to teach information literacy. This includes teaching how to tell fake news from real news, reliable sources from unreliable sources (Journell, 2019; McGrew et al., 2019). This also means teaching people how to search for information more effectively. People may believe that they can effectively search the web, but many people struggle to find answers to complex questions on the web (Russell, 2019; Doroudi et al., 2016). In fact, in studies run by Google, it was found that $90 \%$ of people did not know that they could quickly search for information on a webpage using a simple hotkey (i.e., CTRL+F/CMD+F) (Marks, 2011), a result that is surprising to those of us who use this all the time to rapidly find information in documents and websites. As mentioned earlier, all of this should be in addition to teaching students foundational knowledge (that they may need to memorize!), and frameworks for situating knowledge and integrating it with new information they gather by searching the web.

Before moving on, I would like to point to one other potential consequence of using the Internet as an external source of memory. Recall that Gardner, diSessa, and Feurzeig advocated, in one way or another, for an educational vision that focuses on students specializing in one or more areas. Nickerson questioned whether breadth needs to be sacrificed at the expense of depth, as evident in the quote above where he suggests information technologies may make it possible to know more than ever before. If in today's world we are far from the visions that Gardner, diSessa, and Feurzeig have outlined, I would say we are much further from a world where people are capable of learning much more, as Nickerson has suggested. Nonetheless, I think Nickerson's speculation is worth pondering about, and I believe the answer to increasing how much people can know lies in Pea's notion of "interdisciplinary knowledge transfer" and "synergistic design": "The goal is to make interlinked learning offer greater yield of understanding that the study of disaggregated subjects" (p. 192). Pea laments on how even though reformers have sought for this since at least Francis Parker and John Dewey, before the twentieth century, "the problem of cross-curriculum segregation has not changed much in 110 years" (p. 192). Some have suggested that polymaths of yore were capable of being experts in many areas because there was (comparably) so little to know. But perhaps, it was their reliance on their own memory, the fact that the knowledge they had access to had to be stored and mentally organized in their minds, that enabled them to see connections that would otherwise not be seen. With the Internet at our fingertips, we have access to all the information that polymaths had, but how will we see the interrelations between seemingly disconnected areas? Indeed, Root-Bernstein (2009) argues that polymathy is enabled by combining various areas of knowledge. He cites the findings of historian of science Minor Myers Jr. who found that "creativity is governed by a combinatorial function such that the greater the diversity of knowledge and skill sets that an individual can integrate, the greater the number of novel and useful permutations will result" (Root-Bernstein, 2009). Moreover, contrary to popular belief, Root-Bernstein (2009) argues that polymathy is nearly ubiquitous among the game-changers in science, art, and the formation of new disciplines.

Case in point, the very field of educational technology is replete with polymaths: Seymour Papert (a "literal polymath" in that he held two PhDs in mathematics, although he is more known for his work in education and artificial intelligence), Gordon Pask, Herbert Simon, Patrick Suppes. One could suggest that these individuals were simply geniuses ${ }^{7}$, but I think the key question is what enabled their "genius," and I believe the answer lies,

\footnotetext{
${ }^{7}$ von Foerster (1993), himself a polymath, poetically prefaces his discussion of Pask's genius by saying:
}

When I think of genius, I am not thinking of somebody who can do things much better or much faster than I can do them, but of one who reaches into other dimensions of mentality for which I have no organs, no sense, no language. (p. 35) 
at least in part, in that they saw connections between fields that others did not, or did not know to look for. For example, Simon remarked that "My research career has been devoted to understanding human decision-making and problem-solving processes. The pursuit of this goal has led me into the fields of political science, economics, cognitive psychology, computer science and philosophy of science, among others" (Times, 2001). For Papert, gears played a pivotal role in his childhood and his early understanding of mathematics (Papert, 1980). When he found out that others did not understand or appreciate gears, he asked, "How could what was so simple for me be incomprehensible to other people? My proud father suggested 'being clever' as an explanation" (Papert, 1980). But he later realized what he believed to be "the fundamental fact about learning: Anything is easy if you can assimilate it to your collection of models. If you can't, anything can be painfully difficult" (Papert, 1980).

I think returning to Pea's vision of using technology to support synergistic curricula is worthwhile, and I would say it is not incompatible with supporting depth in one or more areas. For example, having students be semi-experts in two seemingly unrelated areas can help them see novel connections and develop new expertise at the intersection of those areas. Of course, the reason we have not seen synergistic curricula in schools is probably because it is even more difficult than other proposed reforms. But perhaps we can make advances in this area by operating on the margins, as Dewey did with his Laboratory School, and by fostering synergies through out-ofschool learning opportunities, as I touch upon below.

\section{Connected Learning}

More broadly, even if technology is not drastically changing what students are doing in schools, it is changing what learners (of all ages) are doing outside of school. Most of the chapters in Technology in Education consider visions for the future of formal education, and indeed Cohen's analysis primarily applies to schools, whose organizational structures limit the impact of technology and reform. That said, we did just apply Cohen's analysis to Internet usage, and I believe it can be applied generally to say that to the extent that the desired role of educational technology is not compatible with people's incentives, it will not have much impact. We see this for example with educational games, where children have to choose whether to play the latest trending video game or a lack-luster educational game; it is clear which most will choose. To have educational games be more competitive in the market, we can make them more entertaining, but then they might lose their educational value (Dai and Wind, 2011). Instead, we can take the digital media people choose to interact with as entry points to learning. For instance, in addition to creating new educational games, we can bring learning opportunities to games that kids and young adults are already playing, such as Minecraft (Ito, 2015; Niemeyer and Gerber, 2015) or eSports (Anderson et al., 2018; Richard et al., 2018).

These are instances of a new mode of research on digital learning, called connected learning (Ito et al., 2013). Connected learning is based on an agenda that

advocates for broadened access to learning that is socially embedded, interest-driven, and oriented toward educational, economic, or political opportunity. Connected learning is realized when a young person is able to pursue a personal interest or passion with the support of friends and caring adults, and is in turn able to link this learning and interest to academic achievement, career success or civic engagement. (p. 4, emphasis in original)

This movement adequately acknowledges the limitations of prior work on (primarily school-based) educational technology, including the perspectives in Cohen and Malcom's chapters:

Just as in the eras of educational video, computer assisted instruction, and edutainment, today's technologies and techniques have been met with much hope and optimism. Open educational content, personalized learning systems, game-like learning, massively open online courses, and blended learning offers us important and accessible new tools and techniques to reinvigorate learning. Without a broader vision of social change however, new technologies will only serve to reinforce existing institutional goals and forms of social inequity. Many prior attempts to mobilize technology in the service of educational reform have failed because interventions have focused narrowly on the deployment of particular media or technologies, without considering broader social, political, or economic conditions (Ito, 2009; Tyack and Cuban, 1995; Cuban, 2003). 
Unlike efforts at educational change that focus on technology deployment or institutional reform, connected learning takes a networked approach to social change that aligns with our ecological perspective. We believe that systemic shift requires linked efforts across different sites of learning, and that our best hope for educational change lies in connecting like-minded reform efforts across sectors of home, popular culture, technology, and education. Diverse youth, educators, parents, and technology makers coming together around a shared vision of learning can achieve "network effects" where more value is created when the number and diversity of participants are increased (Liebowitz and Margolis, 1994). (Ito et al., 2013, p. 41, emphasis added)

Connected learning takes place in homes when learners connect to their peers online, in public spaces such as libraries and community centers, after-school clubs, camps, etc. Public safe spaces, such as the YOUmedia Learning Labs in the Chicago Public Libraries, allow youth to explore their interests with digital (or non-digital) media and/or meet and hang-out with like-minded peers, serving as an entry point to mentorship opportunities, peer-support networks, and being able to pursue connections between their interests and academic or career pathways (Ito et al., 2013). These spaces could support the interests of students like Raul Gomez who do not have the support structure (both social and technological) at home or at school to pursue their interests. In many ways, connected learning is similar to the visions of Gardner and Feurzeig of promoting specialization based on student interest and apprenticeship, but it does so largely by working outside the framework of traditional schooling environments. It could be said that connected learning spaces are on the margins of educational organizations, which means that they are not as susceptible to Cohen's argument on the limited impact of technology in education. On the other hand, however, they are not marginal to the extent that they can attract and capture wide arrays of youth who have interests in digital media and technology. Taking advantage of both online and physical presence can spread such initiatives to youth who would otherwise lose opportunities to learn and pursue their interests. Indeed, my wife and I found ourselves chancing upon the YOUmedia Learning Lab in the Harold Washington Library while taking a stroll in Downtown Chicago, welcomed into the space and impressed by what they were doing. ${ }^{8}$ Had I been a bit younger and found the right set of peers, maybe I would have played one of the exciting board games they had there (a technology we should not forget about as the digital takes over).

\section{Conclusion: Shaping the Future of Technology in Education}

Technology in Education is a forgotten gem that I contend is worth studying to this day. Its value lies both in the individual chapters-some of which I think still lay out visions for educational reform (regardless of how big a role technology plays) that are worth aspiring to or reflecting on-and in the whole text as an artifact in the "history of the future of education." In its latter role, the book could serve as a guide for thinking about the future of education beyond 2020. This review has begun to do this, but by reflecting on the visions in the book and how they have or have not informed the current state of affairs, there might be more benefit waiting to be gleaned.

To mitigate Cohen and Malcom's pessimistic, but fairly accurate, depictions of the role of technology in education today, we need to design socio-technical solutions that are attuned to the needs, attitudes, and constraints of various educational stakeholders and that ensure equitable outcomes for all learners. In some cases, this may mean co-designing technological solutions with stakeholders of educational organizations operating on the margins (e.g., through research-practice partnerships or networked improvement communities). In other cases, it may mean leading efforts to challenge socio-cultural barriers to productive technology adoption, such as problematic beliefs and attitudes about learning and authority. In yet other cases, it means providing learning support and fostering the socio-cultural institutions and contexts that surround existing technologies that learners are already using out of school, such as the Internet and online games. While new digital technologies could advance learning outcomes in existing educational practice, I believe we also need to focus on preempting how technology is changing society and what it means to learn and know, and make sure education keeps up with the times. Designing these kinds of socio-technical solutions for education requires a concerted effort of not just technologists, but a broader group of researchers, practitioners, and visionaries who are concerned about our educational future-a group like those who brought us Technology in Education: Looking Toward 2020-combined with the students, parents, and teachers that lie at the center of the future of education.

${ }^{8}$ I did not realize at the time that my connected learning colleagues had inspired the design of this space, but I did have a hunch later on that I confirmed. 


\section{References}

Craig G Anderson, AM Tsaasan, Jason Reitman, Je Seok Lee, Minnie Wu, Holly Steel, Tom Turner, and Constance Steinkuehler. Understanding esports as a STEM career ready curriculum in the wild. In 2018 10th International Conference on Virtual Worlds and Games for Serious Applications (VS-Games), pages 1-6. IEEE, 2018.

John R Anderson, Lynne M Reder, and Herbert A Simon. Situative versus cognitive perspectives: Form versus substance. Educational researcher, 26(1):18-21, 1997.

Ryan SJd Baker, Sidney K D’Mello, Ma Mercedes T Rodrigo, and Arthur C Graesser. Better to be frustrated than bored: The incidence, persistence, and impact of learners' cognitive-affective states during interactions with three different computer-based learning environments. International Journal of Human-Computer Studies, 68 (4):223-241, 2010.

Solon Barocas, Moritz Hardt, and Arvind Narayanan. Fairness and Machine Learning. fairmlbook.org, 2019. URL http://www.fairmlbook.org.

Andy Clark and David Chalmers. The extended mind. Analysis, 58(1):7-19, 1998.

Cynthia E Coburn and William R Penuel. Research-practice partnerships in education: Outcomes, dynamics, and open questions. Educational Researcher, 45(1):48-54, 2016.

David K Cohen and Jal D Mehta. Why reform sometimes succeeds: Understanding the conditions that produce reforms that last. American Educational Research Journal, 54(4):644-690, 2017.

Larry Cuban. Teachers and machines: The classroom use of technology since 1920. Teachers College Press, 1986.

D Yun Dai and Alexander P Wind. Computer games and opportunity to learn: Implications for teaching students from low socioeconomic backgrounds. In Computer games and instruction, pages 477-500. 2011.

Shayan Doroudi, Ece Kamar, Emma Brunskill, and Eric Horvitz. Toward a learning science for complex crowdsourcing tasks. In Proceedings of the 2016 CHI Conference on Human Factors in Computing Systems, pages 2623-2634. ACM, 2016.

Elizabeth L Eisenstein. The printing press as an agent of change. Cambridge University Press, 1980.

T. S. Eliot. Choruses from "the rock”. In T. S. Eliot: Collected Poems, 1909-1962. Harcourt, Brace \& World, 1963.

Bill Ferster. Teaching machines: learning from the intersection of education and technology. JHU Press, 2014.

Oscar Firschein, Martin A Fischler, L Stephen Coles, and Jay M Tenenbaum. Forecasting and assessing the impact of artificial intelligence on society. In Proceedings of the Third International Joint Conference on Artificial Intelligence, pages 105-120. IJCAI Organization, 1973.

James G Greeno. On claims that answer the wrong questions. Educational researcher, 26(1):5-17, 1997.

Peter High. For the largest not-for-profit MOOC, edX, experimentation is the path to innovation. Forbes, Jan 2014. URL https://www .forbes.com/sites/peterhigh/2014/01/20/for-the-largest-not-for-profit-mooc-edx-experim

Edwin Hutchins. Cognition in the Wild. Number 1995. MIT press, 1995.

Mimi Ito. Why minecraft rewrites the playbook for learning. Boing Boing, 2015 . URL https://boingboing.net/2015/06/06/why-minecraft-rewrites-the-pla.html.

Mizuko Ito, Kris Gutiérrez, Sonia Livingstone, Bill Penuel, Jean Rhodes, Katie Salen, Juliet Schor, Julian SeftonGreen, and S Craig Watkins. Connected learning: An agenda for research and design, 2013.

Wayne Journell. Unpacking Fake News: An Educator's Guide to Navigating the Media with Students. Teachers College Press, 2019.

Salman Khan. Let's use video to reinvent education. TED, 2011. 
Paul A Kirschner, John Sweller, and Richard E Clark. Why minimal guidance during instruction does not work: An analysis of the failure of constructivist, discovery, problem-based, experiential, and inquiry-based teaching. Educational psychologist, 41(2):75-86, 2006.

F Kuwonu. Radio lessons: In africa, schools are closed but learning goes on. Africa Renewal, 15, 2020.

Paul Marks. Google usability chief: Ideas have to be discoverable. New Scientist, November 2011. URL https://www.newscientist.com/article/mg21228400-400-google-usability-chief-ideas-have-to-be-discovera

Elizabeth J Marsh and Suparna Rajaram. The digital expansion of the mind: Implications of Internet usage for memory and cognition. Journal of Applied Research in Memory and Cognition, 2019.

Sarah McGrew, Mark Smith, Joel Breakstone, Teresa Ortega, and Sam Wineburg. Improving university students' web savvy: An intervention study. British Journal of Educational Psychology, 2019.

Jal Mehta and Sarah Fine. In search of deeper learning: The quest to remake the American high school. Harvard University Press, 2019.

Charles Munter, Mary Kay Stein, and Margaret S Smith. Dialogic and direct instruction: Two distinct models of mathematics instruction and the debate(s) surrounding them. Teachers College Record, 117(11):1-32, 2015.

Raymond S Nickerson and Philip P Zodhiates, editors. Technology in education: Looking toward 2020. Routledge, 1988.

Dodie J Niemeyer and Hannah R Gerber. Maker culture and minecraft: Implications for the future of learning. Educational Media International, 52(3):216-226, 2015.

Nils J Nilsson. The quest for artificial intelligence. Cambridge University Press, 2009.

Seymour Papert. Mindstorms: Children, computers, and powerful ideas. Basic Books, Inc., 1980.

Seymour Papert. A critique of technocentrism in thinking about the school of the future. In Children in the Information Age, pages 3-18. Elsevier, 1988.

Walter C Parker, Jane Lo, Angeline Jude Yeo, Sheila W Valencia, Diem Nguyen, Robert D Abbott, Susan B Nolen, John D Bransford, and Nancy J Vye. Beyond breadth-speed-test: Toward deeper knowing and engagement in an advanced placement course. American Educational Research Journal, 50(6):1424-1459, 2013.

Plato. Phaedrus. In Plato in Twelve Volumes, volume 9. Harvard University Press, 1925 [c. 370 BC].

Matthew H Rafalow. Disciplining play: digital youth culture as capital at school. American Journal of Sociology, 123(5):1416-1452, 2018.

Justin Reich. Two stances, three genres, and four intractable dilemmas for the future of learning at scale. In Proceedings of the Seventh ACM Conference on Learning@ Scale, pages 3-13, 2020.

Justin Reich and Mizuko Ito. From good intentions to real outcomes: Equity by design in learning technologies. Digital Media and Learning Research Hub, 2017.

G Richard, Z Mckinley, and R Ashley. Collegiate eSports as learning ecologies: investigating collaborative learning and cognition during competitions. DiGRA '18 - Proceedings of the 2018 DiGRA International Conference: The Game is the Message, 2018.

Steve Ritter, Michael Yudelson, Stephen E Fancsali, and Susan R Berman. How mastery learning works at scale. In Proceedings of the Third (2016) ACM Conference on Learning@ Scale, pages 71-79. ACM, 2016.

Robert Root-Bernstein. Multiple giftedness in adults: the case of polymaths. In International handbook on giftedness, pages 853-870. Springer, 2009.

Daniel M Russell. The Joy of Search: A Google Insider's Guide to Going Beyond the Basics. MIT Press, 2019. 
Camille L Ryan and Jamie M Lewis. Computer and internet use in the United States: 2015. US Department of Commerce, Economics and Statistics Administration, US ..., 2017.

Gavriel Salomon. Distributed cognitions: Psychological and educational considerations. Cambridge University Press, 1993.

Christo Sims. From differentiated use to differentiating practices: Negotiating legitimate participation and the production of privileged identities. Information, Communication \& Society, 17(6):670-682, 2014.

Betsy Sparrow, Jenny Liu, and Daniel M Wegner. Google effects on memory: Cognitive consequences of having information at our fingertips. Science, 333(6043):776-778, 2011.

Rand J Spiro, Paul J Feltovich, Michael J Jacobson, and Richard L Coulson. Cognitive flexibility, constructivism, and hypertext: Random access instruction for advanced knowledge acquisition in ill-structured domains. Educational technology, 31(5):24-33, 1991.

Los Angeles Times. Herbert a. simon; nobel prize winner, pioneer in artificial intelligence. Los Angeles Times, February 2001.

Sigmund Tobias and Thomas M Duffy. Constructivist instruction: Success or failure? Routledge, 2009.

Heinz von Foerster. On gordon pask. Systems Research, 10(3):35-42, 1993.

Soroush Vosoughi, Deb Roy, and Sinan Aral. The spread of true and false news online. Science, 359(6380):11461151, 2018.

Audrey Watters. The history of the future of education, $2015 . \quad$ URL http://hackeducation.com/2015/02/19/the-history-of-the-future-of-education.

Audrey Watters. Educational crises and ed-tech: A history, 2020. URL http://hackeducation.com/2020/05/06/crisis.

Sam Wineburg. Why learn history (when it's already on your phone). University of Chicago Press, 2018.

Maryanne Wolf. Reader, come home: The reading brain in a digital world. Harper, 2018.

Frances Amelia Yates. Art of Memory. The University of Chicago Press, 1966. 